\title{
The Effect of Peer Group Overlap in Executives' RPE Contracts on Competitive
}

\section{Aggressiveness}

\begin{abstract}
We investigate how peer group overlap within executives' relative performance evaluation (RPE) contracts influences firms' competitive aggressiveness. Conditional on using RPE, we hypothesize and find that if two firms have each other as peers in their respective RPE contracts, this creates a strategic interaction, which in turn increases their competitive aggressiveness. Specifically, firms in growing industries act aggressively by taking more frequent competitive actions, while firms in mature industries act aggressively through taking more complex actions. This also holds for a sample of exogenous changes in peer group overlap and when we compare it to non-RPE firms.
\end{abstract}

Keywords: peer group overlap, strategic interaction, competitive aggressiveness, relative performance evaluation

JEL: J33, J41, L1, M4 


\section{INTRODUCTION}

In this study, we investigate how peer group overlap within relative performance evaluation (RPE) contracts of executives influences firms' competitive aggressiveness. While an RPE contract of a specific firm by definition includes peers against which executives are compared, those peers themselves not necessarily need to use RPE, or if they use RPE, they might not include the focal firm as part of their peer group. We exploit this variation in RPE contract design and argue that peer group overlap (Firm A selects Firm B as peer and vice versa) induces strategic interaction, which increases competitive aggressiveness.

While the prevalence of RPE in executive compensation contracts has long been debated in prior research (see, e.g., Antle and Smith, 1986; Janakiraman et al., 1992), recent evidence suggests that its use has largely increased. For example, in the period from 2006 to 2016, RPE in executive contracts has doubled, and approximately $57 \%$ of the S\&P 500 firms use some form of RPE in their compensation contracts (Bizjak et al., 2018; Equilar, 2017). By incorporating RPE in compensation contracts, firms can filter common noise from performance, thereby increasing contracting efficiency (see, e.g., Baiman and Demski, 1980; Holmström, 1982; Lazear and Rosen, 1981). The extent to which firms benefit from such efficiency gains depends on the competitive environment (e.g., Gong et al., 2011; Matsumura and Shin 2006; Vrettos 2013). For example, Gong et al. (2011) find that the use of RPE increases with product market competition, arguing that increased competition goes hand in hand with a higher degree of common shocks.

In contrast to these prior studies, which focus on the antecedents of RPE adoption, such as competition, we focus on examining the impact of different design features within RPE contracts. In particular, we examine how specific features within RPE contracts influence firms' competitive aggressiveness over and above the existing product market competition. It is important to note that

competitive aggressiveness is not the same as general product market competition. Competitive 
aggressiveness refers to the repertoire of competitive actions a firm takes, such as changes in the pricing strategy, taking legal actions, product changes, or mergers and acquisitions (Ferrier, 2001; Ferrier et al., 1999). As such, even within highly competitive markets, firms can act more or less aggressively.

The RPE contract design feature that we examine is the extent to which there is overlap in the peer groups between firms using RPE. RPE contracts involve peer firms against which executives of the focal firm are being compared. However, these peer firms might or might not use RPE themselves and include the focal firm in their peer group. The higher the fraction of peers that also involve the focal firm in their RPE contracts, the higher the peer group overlap. We argue that this peer group overlap induces strategic interaction between firms, and in turn affects the competitive actions of the firms. Hence, to understand the consequences of adopting RPE contracts, it is important to distinguish RPE contracts that involve peer group overlap from those contracts that do not. Our research design allows us to empirically make this distinction.

If firms overlap in their peer groups, they are in direct performance competition with each other. That is, whenever one firm increases its performance, it automatically decreases relative performance of its peers, and vice versa. This strategic interaction gives executives strong incentives to outperform their peers and hence to take competitive actions that improve their own relative performance (Aggarwal and Samwick, 1999a). In contrast, when RPE contracts do not involve any peer group overlap, strategic interaction among firms is muted and firms will show a relatively lower level of competitive aggressiveness. Thus, while firms will always act competitively aggressive to some extent (Ferrier, 2001), we argue that peer group overlap creates strategic interaction between firms that encourages them to increase their competitive aggressiveness incrementally. 
To test our prediction, we construct a comprehensive dataset using executive compensation information manually retrieved from the Compensation Discussion and Analysis section of the SEC proxy statements. Proxy statements provide information regarding the constituents of each RPE firm's peer group. Using this information, we create a network of all RPE contracts, and measure peer group overlap as the number of overlapping peer relationships scaled by the peer group size for each firm-year. To measure competitive aggressiveness, we use structured content analysis of newspaper headlines and identify the competitive actions of firms. Following the strategic management literature (e.g., Ferrier, 2001; Ferrier et al., 1999; Nadkarni et al., 2016; Ndofor et al., 2011; Rindova et al., 2010), we measure the volume and the complexity of these actions. Importantly, strategic management literature suggests that the specific type of aggressiveness (high volume or high complexity), varies with the competitive environment firms are operating in. While industries in the growth stage are typically associated with high volume strategies, industries in the mature stage are associated with highly complex strategies. Thus, we split our analysis in the different life cycle stages of the industry (i.e., growth and mature phase). To classify industries in the different life cycle stages, we rely on Cantrell and Dickinson's (2018) concept of industry life cycle.

We find that peer group overlap is indeed associated with higher firms' competitive aggressiveness. Specifically, we find that in growing industries firms with higher peer group overlap also take a higher volume of competitive actions; in mature industries, peer group overlap is associated with competitive actions that are more complex. Thus, while firms with higher peer group overlap in RPE contracts show higher competitive aggressiveness, the specific form of how they carry out their aggressiveness differs among the life cycle stages of the industry.

To provide more insights into these associations, in terms of their causal nature, we perform the following analysis. We exploit the fact that when a focal firm's peer adds the focal firm to its 
own peer group, it triggers an exogenous shock to the focal firm's peer group overlap. Thus, we compare the competitive aggressiveness of firms after being added by a peer with an entropy balanced control group of RPE firms without any peer group overlap. Due to the limited amount of changes in the peer groups during the mature phase, we have to restrict this analysis to the growth stage. The results are in line with our main analysis and show that firms in the growth stage show a higher volume of competitive actions in the year after being added to the peer firms peer group compared to firms in the control group.

Moreover, our theory predicts that it is not RPE per se that enhances the strategic interaction and competitive aggressiveness, but the peer group overlap in the RPE contracts. In an additional analysis, we therefore compare the competitive aggressiveness among three types of firms: RPE firms with peer group overlap, (ii) RPE firms without peer group overlap, and (iii) firms not using RPE at all. The results are in line with our theory and show that RPE firms with peer group overlap show higher competitive aggressiveness compared to non-RPE firms, while there are only minor differences between RPE firms without peer group overlap and non-RPE firms.

We also perform the following robustness tests: (i) measure the complexity in the competitive actions with the deviation from industry norms, (ii) replace the industry life cycle indicator with numerous underlying industry characteristics, and (iii) control for the firm-specific life cycle stage. The results are robust to these modifications.

Our study contributes to the literature in several ways. First, we show how RPE contracts are related to firms' competitive aggressiveness. Analytical studies have shown the benefits of using relative performance evaluation to increase contracting efficiency (e.g., Baiman and Demski, 1980; Holmström, 1982; Lazear and Rosen, 1981). Supporting these claims, recent studies show a widespread use of RPE in executives' compensation contracts (Bizjak et al., 2018), and that firms consider their competitive environment in their decision to adopt RPE (e.g., Vrettos 2013; 
Aggarwal and Samwick, 1999a; Gong et al., 2011). We go beyond these studies and show how $\mathrm{RPE}$, and in particular the peer group overlap in RPE contracts, influences firms' decision-making once firms adopt RPE. Such insights improve our understanding of the costs and benefits of RPE contracts.

Second, we decompose RPE contracts and distinguish RPE with peer group overlap and RPE without peer group overlap. While prior literature often treats RPE as a uniform construct, disclosures in the Compensation Discussion and Analysis section of the SEC proxy statements suggest that there is variation in the features of these contracts. In our sample, all the firms that use RPE specify a peer group against which their executives are being compared. However, the extent to which the focal firm is also part of their peers' executive contracts varies. This allows us to isolate the strategic interaction from the noise reduction component in RPE contracts. We show that it is especially peer group overlap that induces the strategic interaction among firms, which increases their competitive aggressiveness. In fact, our results suggest that RPE without peer group overlap has only minor effects on competitive aggressiveness, while peer group overlap in RPE contracts is associated with a significant increase in competitive aggressiveness. It is thus important to distinguish different forms of RPE contracts when examining its effects. This has also significant implications for the transferability of research results from within firm tournaments to executive RPE contracts, and vice versa. While there is typically a peer group overlap in RPE contracts within firms (e.g., Matsumura and Shin 2006), this is not necessarily the case for RPE contracts across firms.

Finally, in studying the effect of peer group overlap on firms' competitive aggressiveness, we combine insights from accounting and strategic management. While competitive actions trigger many accounting-related issues, such as earnings management (e.g., Burgstahler and Dichev, 1997; Roychowdhury, 2006) and disclosure (e.g., Ali, Klasa, Yeung, 2014; Glaeser, 2018; Park, Sani, 
Shroff and White, 2019), the accounting literature has largely ignored the effect of accountingrelated choices on such actions. Given that competitive aggressiveness is an established and validated construct (see, e.g., Ferrier, 2001; Ferrier and Lyon, 2004; Ferrier et al., 1999; Nadkarni et al., 2016; Ndofor et al., 2011), this construct provides amply opportunity for future accounting research.

We organize the remainder of the paper as follows. Section 2 provides relevant background information and develops our hypothesis. Section 3 describes our research design. We discuss our results in Section 4 and provide concluding remarks in Section 5.

\section{BACKGROUND AND HYPOTHESIS}

\subsection{Background}

In his seminal paper, Holmström (1982) develops an economic theory of relative performance evaluation. Analyzing a setting with multiple agents, he shows that if the agent's performance and performance of his peers are exposed to common shocks, it is optimal to include peer performance in the agent's incentive contract. This optimality follows from the opportunity to use peer performance to filter out common noise from performance, leading to more efficient incentives.

The strong theoretical arguments underlying RPE triggered a stream of empirical studies in the mid-1980s and 1990s examining the use of RPE, predominately in the context of executive compensation (see, e.g., Antle and Smith, 1986; Barro and Barro, 1990; Gibbons and Murphy, 1990; Janakiraman et al., 1992). The evidence of these studies on the use of RPE was mixed. However, after the U.S. Securities and Exchange Commission amended the disclosure requirements for executive compensation in 2006, direct evidence suggests that a large fraction of firms uses RPE to evaluate their executives (e.g., Bizjak et al., 2018; Equilar, 2017). Therefore, the 
emphasis has moved towards examining firms' rationale to adopt RPE. In line with the noise reduction argument from Holmström (1982), Albuquerque (2014) and Gong et al. (2011) empirically show that common noise exposure is a notable predictor of using RPE.

However, as Holmström (1982) points out, this efficient use of information induces competition between agents. While he argues that such competition is valueless beyond information extraction purposes, other studies suggest that strategic interaction induced by RPE can be potentially costly to firms. For example, as a consequence of RPE-induced competition, agents may sabotage and shirk (Gibbons and Murphy 1990). Following this logic, Aggarwal and Samwick (1999a) and Vrettos (2013) argue that strategic interaction resulting from RPE can be so costly to firms that in some environments (i.e., product complementarity) they are reluctant to use RPE contracts. However, empirical evidence of whether and how strategic interaction resulting from RPE affects the competitive actions of firms and their aggressiveness is absent. In addition, prior studies that examine issues of strategic interaction typically assume that all agents work under the same compensation scheme, where they directly affect each other's compensation. While such a setting is often observed within firms (e.g., Matsumura and Shin 2006), it is less obvious at an executive level, where RPE contracts are created between firms. For example, when Firm A uses an RPE contract with Firm B included in its peer group, it is not a required that Firm B itself has an RPE contract nor that Firm A is in its peer group, if RPE is used. As we will argue, only if Firm B uses RPE as well and Firm A is included as peer, significant strategic interaction is present, which affects competitive aggressiveness. This is the focus of our study.

\subsection{Competitive aggressiveness}

In an attempt to gain market share and gain a competitive advantage over competitors, firms engage in competitive actions (Ferrier, 2001; Ferrier et al., 1999). As Ferrier (2001) states it: “As they 
navigate the competitive landscape, firms often directly and aggressively challenge competitors in an effort to improve relative performance." A large stream of literature in strategic management examines determinants and consequences of such competitive actions (Chen et al., 2010a; Chen et al., 2010b; Derfus et al., 2008; Eisenhardt and Martin 2000; Ferrier 2001; Ferrier and Lyon 2004; Ferrier et al., 1999; Nadkarni et al., 2016; Ndofor et al., 2011, and Rindova et al., 2010). Competitive actions are moves a firm makes to target its competitors, or countermoves a firm makes in response to its competitors' moves (Hambrick et al., 1996). As an example, a competitive action might include the introduction of a new promotional campaign that disrupts a market, or it may refer to the acquisition of another firm in order to gain synergistic benefits (Ferrier et al., 1999). Collectively, these actions reflect the aggressiveness of the firm. The more frequent those actions are taken, or the more variation in total repertoire of actions, the more aggressively firms act (e.g., Ferrier et al., 1999).

\subsection{Hypothesis Development}

While firms will always act competitively aggressive to some extent (Ferrier, 2001), we argue that peer group overlap in RPE contracts creates strategic interaction among firms, which increases their competitive aggressiveness incrementally over using RPE without peer group overlap. Peer group overlap puts executives in direct performance competition with each other. Whenever one firm increases its performance, it automatically decreases the relative performance of its peers, and vice versa. Thus, the actions of one firm directly impact the performance and compensation of its peers (Holmström, 1982; Lazear and Rosen, 1981). To improve own relative performance and succeed in such a setting, theory suggests that firms increase their aggressiveness (Aggarwal and Samwick, 1999a; Lazear and Rosen, 1981). However, when executives utilize an aggressive competitive strategy in such a setting, peers are likely to strike back by increasing their competitive 
aggressiveness towards the focal firm as well. Hence, both firms adopt an aggressiveness strategy to outperform each other. In contrast, without peer group overlap, this strategic interaction between the focal RPE firm and its peers is muted. In such a setting, firms are less likely to adopt a competitively aggressive strategy to outperform each other.

While we argue that peer group overlap increases competitive aggressiveness, firms could alternatively collude with overlapping peers by not taking competitive actions towards each other. Given legal restrictions (i.e., antitrust and competition laws), such a scenario would be based on trust between firms, though. As soon as executives get doubtful about the reliability of these arrangements and expect a competitive action of peers at some point in time, this anticipation is sufficient to unravel the collusion based on trust. As a result, while such a scenario is possible, it is less likely to play out in practice. Therefore, we predict that the greater peer group overlap, the greater competitive aggressiveness. More formally:

H1: Peer group overlap is positively associated with competitive aggressiveness.

\section{RESEARCH DESIGN}

\subsection{Identifying RPE firms}

To examine our research question, we must first identify RPE contracts in executives compensation. We follow Gong et al. (2011), Park and Vrettos (2015), and Vrettos (2013), and hand collect data for the fiscal years 2012 through 2014 from the proxy statements of the S\&P 1,500 firms using the Securities and Exchange Commission's EDGAR database. We examine the Compensation Discussion and Analysis section of the proxy statements and identify the presence of an RPE contract for a firm-year observation if (i) the firm's proxy statement explicitly states that at least one component of executive compensation is determined based on the firm's performance 
relative to performance of other firms, and (ii) the firm uses and explicitly states the self-selected performance peer group. ${ }^{1}$ Appendix A exemplifies an RPE contract for Unit Corporation. Our final sample consists of 181 unique RPE firms with 472 firm-year observations.

\subsection{Measuring Peer Group Overlap}

We identify peer group overlap by analyzing all firm-peer relationships and record which relationships are "singular" and which are "dual". Singular peer relationships are those relationships whereby the focal firm has another firm selected as a peer, but this peer firm does not have the focal firm as a RPE peer. In a dual peer relationship the peer firm also has the focal firm selected as peer. Thus, if a relationship is dual, there is a "peer group overlap". We then count the number of overlapping peer relationships per firm-year and scale that by the peer group size for that firm-year. The higher the fraction of dual relationships in an RPE contract, the higher the peer group overlap.

\subsection{Measuring Competitive Aggressiveness}

To measure the competitive aggressiveness, we follow strategic management literature and measure the volume of competitive actions, and the complexity of the competitive actions. The volume captures the total number of competitive actions within a given period. The more actions a firm takes, the higher its competitive aggressiveness. However, not all actions are identical launching a new marketing campaign is a fundamentally different action than suing competitors. Therefore, actions can be classified into different categories such as capacity, legal, marketing, pricing, and product (Ferrier et al., 1999). Taking actions from various categories simultaneously

\footnotetext{
${ }^{1}$ Firms that use indexed peer groups are excluded from our study, because we are primarily interested in the effect of peer group overlap resulting from explicit peer selection by boards. When indexed peer groups are used in RPE contracts, performance is simply measured against the median performance of that index. Hence, the constituents of the index are not directly observable for those executives, implying that no real strategic interaction exists. Besides, firms that use peer groups solely to benchmark the level of compensation are coded as non-RPE firms.
} 
can be even more harmful for competitors than merely doing more of one category. Therefore, another commonly used measure of competitive aggressiveness is competitive complexity, which captures the breadth of a firm's repertoire of competitive actions. ${ }^{2}$ The higher the complexity, the more aggressive a firm acts.

To identify the competitive actions, we use structured content analysis of newspaper headlines (e.g., Ferrier, 2001; Nadkarni et al., 2016; Rindova et al., 2010). We use the LexisNexis database to collect all the newspaper headlines related to our sample firms in the sample period. In order to be included in our dataset, headlines need to be written in English and have the firm name in the title. Moreover, we require that the firm index associated with the news article assigned by LexisNexis matches the firm we search for and remove duplicate headlines. Appendix B provides example headlines.

To measure the volume dimension of competitive aggressiveness, we sum up all the actions of a firm per year. For the complexity measure, we need to classify the headlines in different categories. Using a machine learning algorithm, we classify the headlines into the following categories: capacity, legal, marketing, pricing, and product (Ferrier et al., 1999). We then relate the actions in the different categories to the overall number of actions and subtract this fraction from 1 to derive at our complexity measure. Formally, the measures of volume and complexity are defined as follows:

$$
\text { Aggressiveness Volume }=\sum_{i=1}^{n} a_{i j}=T_{j}
$$

\footnotetext{
2 The strategic management literature also discusses other forms of competitive aggressiveness such as the deviance from industry norms, speediness, and the order of strategic actions (see, e.g., Chen et al., 2010b; Derfus et al., 2008; Ferrier, 2001; Ferrier et al., 1999; Nadkarni et al., 2016; Ndofor et al., 2011). In a follow-up analysis we examine the effect on the deviance from the industry norms. The results are largely in line with our main results. However, given the strong overlap of these measures, we focus on the two most frequently used components in literature in our main analysis, i.e., volume and complexity.
} 
Aggressiveness Complexity $=1-\sum_{i=1}^{n}\left(a_{i j} / T_{j}\right)^{2}$

where $a_{i j}$ is the number of firm $j$ 's actions in the $i$ th action category, $T_{j}$ is the total number of actions carried out by firm $j$ in a given year, and $n$ is the total number of action categories.

\subsection{Capturing Competitive Environment}

While both the volume and the complexity of the competitive actions proxies for the competitive aggressiveness of firms, the strategic management literature suggests that the focus of firms on either of these dimensions changes with the competitive environment firms are operating in (see, e.g., Chen et al., 2010a; Covin and Covin, 1990; Ferrier, 2001; Rindova et al., 2010). That is, in fast changing environments like growth industries, firms typically rely on competitive actions that are simple and predictable - and as such are easier to grasp - because that strategy yields superior market valuations compared to more complex strategies (Chen et al., 2010a; Chen et al., 2010b; Eisenhardt and Martin, 2000; Rindova et al., 2010). In contrast, in more mature and stable markets, longer time horizons and often better information warrant more sophisticated strategies where firms use a broader repertoire of actions (Eisenhardt and Martin, 2000; Nadkarni et al., 2016).

Given that firms use different strategies to achieve their desired level of competitive aggressiveness in different life cycle stages of the industry, we also have to split our analysis accordingly. Doing so allows us to estimate the effect of peer group overlap on those dimensions of competitive aggressiveness that are the dominant strategies in their respective life cycle stages. As pointed out before, prior literature has shown that simple and high volume strategies are typically associated with firms in the growth stage. Thus, if peer group overlap is associated with a higher level of aggressiveness, we expect that firms increase their volume of competitive actions when the industry is in the growth stage. In contrast, in the mature stage of the industry life cycle, we expect that higher aggressiveness induced by peer group overlap is associated with higher 
complexity in firms' actions. Thus, we split our analysis in the different life cycle stages of the industry to avoid underestimating the effect of peer group overlap on competitive aggressiveness.

To empirically capture the different life cycle stages of the industry, we use the measure developed by Cantrell and Dickinson (2018). Therefore, we aggregate for each industry the firm life cycles based on the patterns of operating, investing, and financing cash flows as defined by Dickinson (2011), where the industry classification follows the 48 industry groups identified by Fama and French (1997). The industry life cycle is then defined as the life cycle stage where most of the firms of the industry are in. In our sample, there are no industries operating in the shake-out or decline stage, and only a small number of firms operating in industries in the introduction stage. ${ }^{3}$ Hence, our analyses will focus on the two remaining stages: growth and mature. ${ }^{4}$

\subsection{Empirical models}

In our hypothesis, we predict that peer group overlap increases firms' competitive aggressiveness.

To test our hypothesis, we estimate the following equations for the growth and mature industry life cycle stages separately, using seemingly unrelated regressions:

\footnotetext{
${ }^{3}$ This is not surprising, but rather consistent with the finding in Cantrell and Dickinson (2018) that nearly 89 percent of the industries is in either the introduction, growth or mature stage.

${ }^{4}$ One could argue that the introduction stage is quite similar to the growth stage. Our results are robust to pooling firms in the introduction stage with firms in the growth stage.
} 
$\log _{e}$ Aggressiveness Volume $_{i, t}=$

$\alpha_{0}+\beta_{1}$ Peer Group Overlap ${ }_{i, t}+\beta_{2}$ Peer Group Synchroncity $_{i, t}+$

$\beta_{3}$ H\&P Number of Peers ${ }_{i, t-1}+\beta_{4}$ H\&P Peer Similarity ${ }_{i, t-1}+$

$\beta_{5}$ Size Percentile $_{i, t-1}+\beta_{6}$ Tobin's q Percentile $_{i, t-1}+\beta_{7}$ Leverage Percentile $_{i, t-1}+$

$\beta_{8}$ Returns Percentile $_{i, t-1}+\beta_{9} \operatorname{Loss}_{i, t-1}+\gamma^{\prime}$ Year and Industry Indicators +

$\varepsilon_{i, t}$

Aggressiveness Complexity $_{i, t}=$

$\alpha_{0}+\beta_{1} \log _{e}$ Aggressiveness Volume $_{i, t}+\beta_{2}$ Peer Group Overlap ${ }_{i, t}+$

$\beta_{3}$ Peer Group Synchroncity ${ }_{i, t}+\beta_{4}$ H\&P Number of Peers ${ }_{i, t-1}+$

$\beta_{5}$ H\&P Peer Similarity ${ }_{i, t-1}+\beta_{6}$ Size Percentile $_{i, t-1}+\beta_{7}$ Tobin's q Percentile $_{i, t-1}+$

$\beta_{8}$ Leverage Percentile $_{i, t-1}+\beta_{9}$ Returns Percentile $_{i, t-1}+\beta_{10} \operatorname{Loss}_{i, t-1}+$

$\gamma^{\prime}$ Year and Industry Indicators $+\varepsilon_{i, t}$

where $i$ and $t$ index firm and year, respectively. Descriptions of all variables are presented in Appendix B.

In Eq. (4), where the dependent variable is Aggressiveness Complexity, we additionally control for firms' competitive volume. The reason for this inclusion is that variation in complexity between observations can simply arise due to increased aggressiveness volume. For example, if a firm has a very low volume, its complexity will all else equal be low as well. To isolate the complexity from the volume effect, we control for the volume in the complexity estimations. Further, conceptually we have argued that strategic interaction induced by peer group overlap can be a consequence of exploiting RPE's noise reduction. Consequently, a firm's level of strategic interaction would naturally correlate with its level of noise reduction. To control for this effect, we include a proxy for the firm's level of noise reduction in our estimation. We capture a firm's level of noise reduction by measuring the firm's stock return synchronicity with its peers (Durnev et al., 2003; Morck et al., 2000; Piotroski and Roulstone, 2004). Specifically, for each firm-year observation, we regress the firm's daily returns on the daily returns of all peers for a period of three years. Peer group synchronicity is then measured as a logarithmic transformation of the $R^{2}$ obtained 
from that estimation, to create an unbounded continuous variable out of the variable originally bounded by 0 and 1 . By construction, high values in this measure indicate firms whose stock returns are closely tied to peers stock returns and, hence, measure high levels of noise reduction. The correlation between the level of noise reduction and peer group overlap is positive and significant $(\mathrm{p}<0.01$, two-tailed $)$.

We include two proxies of product market competition, to control for the fact that our RPE strategic interaction proxy may capture some variation attributable to regular product market competition instead. We control for the number of product market competitors and their similarity with the focal firm, as defined by Hoberg and Phillips (2010, 2016). Moreover, to control for industry factors and time trends, we include industry fixed effects based on the 48 industry groups identified by Fama and French (1997) and year fixed effects in our estimations. We opt to control for industry fixed effects based on Fama and French's classification rather than Hoberg and Phillips' classification, since our equations already include measures of product market competition as defined by Hoberg and Phillips (2010, 2016). Hence, inclusion of Fama and French's industry fixed effects allows us to incrementally control for a different set of industry drivers. ${ }^{5}$ Further, we control for firm-specific fundamentals that may affect competitive aggressiveness. Specifically, we control for the relative firm's size (natural logarithm of total assets), growth opportunities (natural logarithm of Tobin's q), leverage (natural logarithm of debtto-equity ratio) and stock returns, all calculated as a percentile compared to the RPE firm's peers at the beginning of the period. We do so as the relative standing within the peer group is more important for strategic interaction of a firm with its peers than the absolute fundamentals of the

\footnotetext{
${ }^{5}$ The results are robust to different industry classifications. Tests using the 25 or 50 FIC industry groups identified by Hoberg and Philips $(2010,2016)$ as industry fixed effects produce similar significant results.
} 
firms, which can be heavily influenced by industry characteristics. Finally, we also include an indicator variable for firms that made a loss in the previous period.

\section{RESULTS}

\subsection{Descriptive Statistics}

Descriptive statistics are summarized in Table 1. Panel A presents summary statistics for the full RPE sample. Panel B presents $t$-tests for differences in mean summary statistics between RPE firms with and without peer group overlap. Pearson correlation coefficients among all variables are presented in Table 2. Peer Group Overlap has a mean value of 0.140 , indicating that approximately one in seven firm-peer relationships is an overlapping peer relationship. The competitive aggressiveness variables are moderately correlated with each other. The uncorrelated fraction, however, indicates that these variables capture distinct variance and, thus, distinct dimensions of competitive aggressiveness.

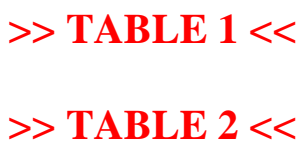

\subsection{Peer Group Overlap and Competitive Aggressiveness}

Table 3 presents the results of estimating Eqs. (3) and (4), which model competitive aggressiveness as a function of peer group overlap and the control variables. We estimate and present the equations for each competitive environment separately. Columns (1) and (2) presents the results for the growth stage, and columns (3) and (4) present the results for the mature stage.

In the growth stage, we find that peer group overlap is significantly associated with firms' competitive aggressiveness. Specifically, Peer Group Overlap shows a positive and significant relationship with Aggressiveness Volume in column (1) ( $\mathrm{p}<0.05$, two-tailed). With respect to the 
complexity dimension (column 2), we find no significant association with Peer Group Overlap. These findings are consistent with our prediction that peer group overlap in growing industries encourages firms to act aggressively by taking a higher volume of actions. Interestingly, we also find a positive and significant relationship between $H \& P$ Number of Peers and Aggressiveness Volume ( $\mathrm{p}<0.10$, two tailed). This suggests that if there is a stronger competition in the product market among the RPE firms, firms get more aggressive. Moreover, firms with strong noise reduction effects take less complex actions, indicated by the negative relationship between Peer Group Synchronicity and Aggressiveness Complexity in column (2) ( $p<0.10$, two tailed).

In the mature stage, we also find that peer group overlap is significantly associated with firms' competitive aggressiveness. Specifically, Peer Group Overlap shows a positive and significant relationship with Aggressiveness Complexity in column (4) ( $p<0.01$, two tailed). With respect to the volume dimension (column 3), we find no significant relationship. These findings are in line with our prediction that peer group overlap in the mature stage encourages firms to act aggressively through taking more complex actions. Contrary to the growth stage, the effect of regular product market competition is in the opposite direction, as indicated by the negative and significant relationship between $H \& P$ Number of Peers and Aggressiveness Complexity in column (4) $(\mathrm{p}<0.01$, two tailed).

Altogether, the results in Table 3 support our hypothesis and indicate that if there is higher peer group overlap firms' also show a higher competitive aggressiveness. While peer group overlap is associated with higher aggressiveness volume in growth environments, it is associated with more complex actions in mature environments.

> TABLE $3<<$ 


\subsection{Exogenous Peer Group Changes}

To corroborate our findings and dig deeper into the causal nature of our results, we exploit the fact that the level of peer group overlap may vary over time, e.g., when adjustments to peer groups are made. If a firm decides to modify its peer group such that newly added peers result in overlapping peer relationships, the increase in peer group overlap can be considered to be endogenous. However, for the peer that gets added, such an addition is an exogenous shock affecting its peer group overlap. Therefore, we examine all peer group composition changes for our sample and identify which changes exogenously affect peer group overlap, by either an addition or removal of a peer. We find 30 additions and seven removals affecting peer group overlap, of which 28 additions and six removals occur in the growth stage. Due to the limited number of removals, we focus our analysis on the 28 additions in the growth stage.

We expect that firms that are exogenously added as peers ("treatment group") respond by increasing their competitive aggressiveness. The limited number of observations restricts our statistical power, therefore, we opt for weighted $t$-tests using an entropy balanced control group to control for potential differences between the groups (Hainmueller, 2017). Specifically, we examine the treatment group's competitive aggressiveness in the year after the exogenous addition, with a similar-sized entropy balanced control group of RPE firms that have no peer group overlap at all. We balance on the natural logarithm of Aggressiveness Volume and Aggressiveness Complexity in the current year, and significant predictors in Eqs. (3) and (4), i.e., Size Percentile, Tobin's $q$ Percentile, Year Indicators and Industry Indicators. After balancing, none of the differences in the two aggressiveness variables, Size Percentile, Tobin's q Percentile, Year Indicators and Industry Indicators is significant (all $\mathrm{p}>0.98$ ).

Table 4 presents the results of the weighted $t$-tests for differences in the competitive aggressiveness between the treatment and control group in the year after the exogenous addition. 
We find that the treatment group's competitive aggressiveness is significantly higher subsequent to the exogenous addition to another firm's peer group. Specifically, we find that the treatment group's Aggressiveness Volume is significantly higher compared to the control group $(\mathrm{p}<0.10$, one-tailed). For the Aggressiveness Complexity we do not find a significant difference. These findings are consistent with our main findings and indicate that peer group overlap increases competitive aggressiveness by encouraging firms to take more frequent actions when industries are in the growth stage.

\section{> TABLE $4<<$}

\subsection{RPE Firms versus Non-RPE Firms}

The main argument of this paper is that peer group overlap within RPE contracts creates significant strategic interaction, which affects the competitive aggressiveness. One concern could be that the peer group overlap is a rather small component in explaining the competitive aggressiveness compared to what RPE contracts in general induce. Inconsistent with such concerns, Aggarwal and Samwick (1999a, 1999b) show in their model that strategic interaction between two firms is considerably higher if both firms use a contract based on peer performance. If only one firm uses a contract based on peer performance, the increase in strategic interaction compared to non-RPE settings is rather small. This suggests that the peer group overlap component is more important in explaining the competitive aggressiveness compared to RPE in general. To examine this argument empirically, we extend our main analysis in this section and investigate whether RPE itself has an effect on competitive aggressiveness, compared to non-RPE firms.

We estimate modified versions of Eqs. (3) and (4), whereby we include an indicator variable for RPE firms (RPE), benchmarked against non-RPE firms, and an interaction between $R P E$ and Peer Group Overlap to examine the incremental effect of peer group overlap (setting Peer Group 
Overlap equal to zero for all non-RPE firms). ${ }^{6}$ In addition, we replace the control variables based on the firm's percentile rank compared to its peer group with similar variables computed based on the group of product market competitors as defined by Hoberg and Phillips $(2010,2016)$, because non-RPE firms do not have an RPE peer group.

Table 5 presents the results of estimating the modified versions of Eqs. (3) and (4). Similar to the main analysis, we estimate and present the equations for the different industry life cycle stages separately. Columns (1) and (2) present the results for the growth stage, and columns (3) and (4) present the results for the mature stage. In the growth stage, we find that $R P E$ is not significant, whereas RPE $\times$ Peer Group Overlap is significantly positively associated with Aggressiveness Volume ( $\mathrm{p}<0.05$, two-tailed). Further, RPE + RPE $\times$ Peer Group Overlap is significantly different from zero $(\mathrm{p}<0.05$, two-tailed). This indicates that competitive aggressiveness in the growth stage is not significantly different between non-RPE firms and RPE firms without any overlap, while RPE firms with peer group overlap have significantly higher competitive aggressiveness compared to non-RPE firms. In the mature stage, we find that RPE firms without overlap have higher volume $(\mathrm{p}<0.01$, two-tailed) and lower complexity $(\mathrm{p}<0.10$, two-tailed) compared to non-RPE firms. This strategy is inconsistent with the optimal strategies identified in the strategic management literature. In contrast, the effect of peer group overlap in RPE contracts is consistent with the strategy identified in strategic management literature. We find that both RPE $\times$ Peer Group Overlap and RPE $+R P E \times$ Peer Group Overlap are significantly positive with respect to Aggressiveness Complexity $(\mathrm{p}<0.05)$ and significantly negative with respect to Aggressiveness Volume $(\mathrm{p}<0.05)$. These results show that peer group overlap is

\footnotetext{
${ }^{6}$ The non-RPE group consists of S\&P 1500 firms that do not use RPE for executive performance evaluation purposes, whereby we exclude the financial and utilities sector.
} 
associated with lower aggressiveness volume and higher aggressiveness complexity compared to non-RPE firms in the mature stage. This is consistent with our main findings.

Taken together, these results show that compared to non-RPE firms, RPE without peer group overlap has no effect during the growth stage and affects competitive aggressiveness in the opposite direction of what theory would suggest in the mature life cycle stage. We do not have a clear explanation for this surprising finding during the mature stage, but leave it to future research to examine this in further detail. However, more importantly, the results show that peer group overlap in RPE contracts indeed is associated with higher aggressiveness compared to non-RPE firms, as indicated by their increased volume during the growth stage and higher complexity during the mature stage. Thus, peer group overlap in RPE contracts is a crucial component to increase the competitive aggressiveness, while RPE itself has only minor effects.

$$
\text { > TABLE } 5<<
$$

\subsection{Robustness Checks}

We perform several supplementary checks to test the robustness of our main results.

\subsubsection{Aggressiveness Deviance}

Based on prior arguments brought forward in the strategic management literature, we consider the complexity dimension to be the appropriate measure of competitive aggressiveness for the mature stage of the industry. Critics might argue that it is not the complexity of the actions how firms act aggressively in the mature stage, but whether they deviate from the industry norms. Therefore, we extend our main analysis and compute a measure of aggressiveness dissimilarity or deviance from industry norms (Ferrier et al., 1999; Ndofor et al., 2011).

To get an accurate estimate of the "industry norm" complexity, we gather competitive aggressiveness data for the non-RPE group, and supplement it with our RPE data. We then group 
our data by the 50 text-based fixed industry classifications (FIC) identified by Hoberg and Phillips (2010, 2016) and year, and compute for each industry-year the average proportion of actions for each action category (i.e., capacity, legal, marketing, pricing and product). For each firm, we subsequently compute the deviation from the average proportion for each category, square all deviations, and sum it. The result is a measure bounded between zero and one that captures the extent to which a firm's competitive repertoire differs from industry norms. More formally:

$$
\text { Aggressiveness Deviance }=\sum_{i=1}^{n}\left(a_{i j} / T_{j}-\left(\overline{a_{i} / T}\right)\right)^{2}
$$

where $a_{i j}$ is the number of firm $j$ 's actions in the $i$ th action category, $T_{j}$ is the total number of actions carried out by firm $j$ in a given year, $\left(\overline{a_{i} / T}\right)$ is the industry mean proportion (excluding the focal firm) of the ith action category, where the industry indicators follow the 50 FIC industry groups, and $n$ is the total number of action categories.

Table 4 presents the results of re-estimating Eq. (3), whereby we replace the dependent variable with Aggressiveness Deviance. ${ }^{7}$ For completeness, we run the regression for both the growth (column 1) and the mature stage (column 2). The findings are similar to our findings regarding the complexity dimension. Specifically, as expected, we find no significant relationship between Peer Group Overlap and Aggressiveness Deviance in the growth stage, whereas we find a positive and significant relationship in the mature stage $(\mathrm{p}<0.05$, two tailed). This provides additional evidence for our hypothesis and shows that the complexity induced by peer group overlap in mature environments is associated with more unique aggressiveness strategies.

$$
>\text { TABLE } 6<<
$$

\footnotetext{
${ }^{7}$ In this model, we do not explicitly control for Aggressiveness Volume. For Aggressiveness Deviance this is not necessary, because Aggressiveness Deviance basically compares the firm's Aggressiveness Complexity with the firm's industry average Aggressiveness Complexity. Thus, the volume effect cancels out in this computation.
} 


\subsubsection{Additional Competitive Environment Proxies}

In our main analysis, we split our analysis in the different life cycle stages of the industry, using the comprehensive industry life cycle measure from Cantrell and Dickinson (2018). In this section, we test the robustness of our results using alternative proxies for the competitive environment. Specifically, we use the level of product market competition (Hoberg and Phillips, 2010, 2016), the level of product substitutability, entry costs, concentration and the size of the industry (Karuna, 2007), the industry average return on assets, industry average net financial obligations (Dickinson, 2011), industry average level of risk-taking (Armstrong and Vashishtha, 2012) and the industry average level of investments (Richardson, 2006) to corroborate our main analysis.

Table 7 presents the means and results of the $t$-tests for differences in the underlying components between the growth and mature stages. Industries in the growth stage have larger product market competition, higher product substitutability, higher entry costs, lower concentration, and are larger. ${ }^{8}$ Besides, industry in the growth stage have higher net financial obligations, higher risk-taking, and higher investment levels.

Subsequently, we re-estimate Eqs. (3) and (4), but instead of estimating separate equations for each competitive environment, we interact Peer Group Overlap with each of the underlying proxies. In untabulated results, we find that seven out of the ten alternative specifications show patterns consistent with our main findings (the exceptions are the specifications where the additional proxy is $H \& P$ Median Similarity, Product Substitutability, and Concentration). Hence, we conclude that our earlier findings are robust to using alternative measures for the competitive environment.

\section{> TABLE $7<<$}

\footnotetext{
${ }^{8}$ Growing industries in our sample are larger in terms of assets, mainly because the oil and gas industry is classified as a growing industry due to its significant growth in the period preceding 2014.
} 


\subsubsection{Firm Life Cycle}

Cantrell and Dickinson (2018) show that firms that are leaders or laggards have different strategies. In their study, leaders (laggards) are defined as firms that are in a firm life cycle leading (lagging) the industry life cycle. Taking their finding into account, we re-estimate all equations in our study, whereby we also include the firm's life cycle as a control variable to control for this leader/laggard effect. Untabulated results indicate that the firm's life cycle does not explain much variation in our aggressiveness measures. We only find that mature firms in growing industries have higher aggressiveness volume ( $\mathrm{p}<0.01$, two-tailed). Most importantly, our main findings are robust to controlling for firm life cycle.

\section{CONCLUDING REMARKS}

This study investigates how peer group overlap in RPE contracts influences competitive aggressiveness. Specifically, we exploit variation in peer group overlap (Firm A selects Firm B as peer and vice versa), and hypothesize that this overlap induces strategic interaction between those firms. The results are in line with our prediction and show that higher peer group overlap is associated with increased firms' competitive aggressiveness. Specifically, the results show that in

growing environments, firms with higher peer group overlap take more frequent competitive actions, while firms operating in mature environments act more aggressively by taking more complex actions, which deviate from industry norms.

Our study contributes to the literature by isolating the strategic interaction component, which can, but not necessarily is present in RPE contracts, from the noise reduction component of RPE. We provide evidence that RPE contracts affect firms' competitive aggressiveness when strategic interaction is induced by peer group overlap. In contrast to prior studies that often neglect the strategic interaction component, our study explicitly exploits differences in RPE contracts with 
and without strategic interaction by identifying its effect on executives' decisions. By distinguishing this element, we provide important insights for future research and, more practically, for boards designing executive compensation contracts. 


\section{APPENDIX A. EXAMPLE RPE CONTRACT}

The following text is an excerpt from the proxy statement of Unit Corporation, where the board explains the use of RPE (Unit Corporation, 2015).

To further increase the tie of NEO [Named Executive officers] pay to performance, the committee increased the performance-based component of the awards to 40\% from the 30\% it had used in prior years. The time-vested $60 \%$ of the award vests in three equal annual installments starting March 9, 2015. The performance-based shares will vest in an amount that will be determined based on application of the following formula, which measures total stockholder return as compared to that of the 2014 Peer Group: ${ }^{9}$

Total Stockholder Return ("TSR") $=\frac{\text { Ending stock price-Beginning stock price }+ \text { Dividends }}{\text { Beginning stock price }}$

For purposes of the formula, the ending and beginning common stock price used will be calculated using the average of the closing price of our common stock on the NYSE for the 15-trading-day period ending on the start and end of the designated performance period (February 18, 2014 to February 18, 2017) and the peer companies' stock prices will be determined in the same manner.

The committee believes that TSR is a readily understood and commonly used measure of corporate performance, and that a comparison of the company's TSR to that of a group of our peer companies is a useful measure of our performance on a relative basis. The committee also believes that using TSR as a measure aligns our management with our stockholders.

The number of performance-based shares that ultimately vest for the NEOs will be determined by the TSR of the company relative to the TSR of the 2014 Peer Group at the end of the performance period, as follows:

\begin{tabular}{crr}
$\begin{array}{c}\text { Company's Performance Percentile Rank } \\
\text { (Unit TSR vs. Peer TSR) }\end{array}$ & $\begin{array}{c}\text { Vesting } \\
\text { (\% that will vest) }\end{array}$ \\
\hline & $>90 \%$ & $150 \%$ \\
& $90 \%$ & $150 \%$ \\
& $75 \%$ & $125 \%$ \\
& $60 \%$ & $100 \%$ \\
& $50 \%$ & $75 \%$ \\
& $40 \%$ & $50 \%$ \\
& $<40 \%$ & $0 \%$
\end{tabular}

Interpolation will be used to determine the percentage of the awards that will vest when performance falls between the percentile ranks set forth in the table above.

9 In February 2014, when our NEOs' 2014 long-term incentive compensation was determined, the committee approved a peer group consisting of the following companies (the "2014 Peer Group") :

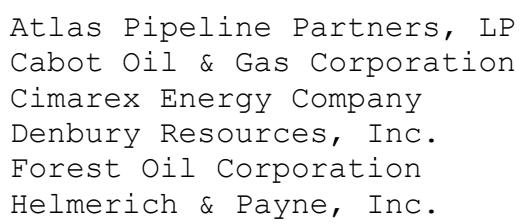

\author{
Newfield Exploration Company \\ Parker Drilling Company \\ Patterson - UTI Energy, Inc. \\ Pioneer Energy Services Corporation \\ SM Energy Company \\ Whiting Petroleum Corporation
}

Unit Corporation, (2015, p. 24). 


\section{APPENDIX B. VARIABLE DEFINITIONS AND MEASUREMENT}

See Table B1.

Table B1

This table describes all variables used in this paper and if necessary calculations and external sources.

Panel A: Aggressiveness

Aggressiveness Volume

Aggressiveness Complexity

Aggressiveness Deviance
Proxy variables for a firm's competitive aggressiveness for the period indicated by the subscript. Aggressiveness Volume captures the total number of competitive actions. Aggressiveness Complexity captures the extent to which a firm's repertoire of actions is composed of actions of different types. Aggressiveness Deviance captures the extent to which a firm's competitive repertoire deviates from industry norms.

The computation is as follows. To capture a firm's competitive actions, we utilized a structured content analysis approach based on newspaper headlines identified in LexisNexis for each firm's fiscal period 2012-2014. We used an algorithm to classify the newspaper headlines into the following preestablished categories: capacity, legal, marketing, pricing and product. This methodology is established in the competitive dynamics literature to measure the competitive actions of firms (see, e.g., Ferrier, 2001; Ferrier and Lyon, 2004; Ferrier et al., 1999; Ndofor et al., 2011). Subsequently, we compute the following variables:

$$
\begin{aligned}
& \text { Aggressiveness Volume }=\sum_{i=1}^{n} a_{i j}=T_{j} \\
& \text { Aggressiveness Complexity }=1-\sum_{i=1}^{n}\left(a_{i j} / T_{j}\right)^{2} \\
& \text { Aggressiveness Deviance }=\sum_{i=1}^{n}\left(a_{i j} / T_{j}-\left(\overline{a_{i} / T}\right)\right)^{2}
\end{aligned}
$$

where

- $a_{i j}$ is the number of firm $j$ 's actions in the $i$ th action category

- $\quad T_{j}$ is total number of actions carried out by firm $j$ in a given year

- $\left(\overline{a_{i} / T}\right)$ is the industry mean proportion (excluding focal firm) of the $i$ th action category, where industries are defined based on the 50 industry groups identified by Hoberg and Phillips (2010, 2016)

- $\quad n$ is the total number of action categories

Example of newspaper headlines include:

- Abbott completes acquisition of medical device firm Topera for $\$ 250 \mathrm{~m}$ (capacity)

- Electronic Arts sues Zynga for copyright infringement (legal)

- Aetna sponsors the Delta Foundation Walk in Washington (marketing)

- Ford cuts price of 2014 focus electric compact car by $10 \%$ to draw consumers (pricing)

- McDonald's launches 'Batman Burger' (product)

(continued on next page) 
Table B1 (continued)

This table describes all variables used in this paper and if necessary calculations and external sources.

\section{Panel B: RPE and Peer Group Attributes}

RPE

An indicator variable equal to one if the firm's proxy statement explicitly states that at least one component of executive compensation is determined based on the firm's performance relative to the performance of other firms in the period indicated by the subscript, zero otherwise.

For example: "Performance shares are earned on the basis of our Total Shareholder Return ("TSR") measured over a three year period, relative to the TSR of the following 12 companies: C.H. Robinson Worldwide, Inc.; Con-way, Inc.; Expeditors International of Washington, Inc.; FedEx Corporation; Hub Group, Inc.; J.B. Hunt Transport Services, Inc.; Knight Transportation, Inc.; Landstar System, Inc.; Old Dominion Freight Line, Inc.; United Parcel Service, Inc.; UTi Worldwide, Inc.; and Werner Enterprises, Inc." (Forward Air Corporation, 2015, p. 23).

Peer Group Overlap

The number of firm-specific overlapping peer relationships scaled by the total peer group size of that firm for the period indicated by the subscript. An overlapping peer relationship is present if two firms have a (i) an RPE contract, and (ii) both have each other self-selected as peer for performance evaluation purposes.

In the example below, peer group overlap for Firm $\mathrm{A}$ is 0.4 . The reasoning is as follows. Firm A has five peers, of which two peers (B and C) do not have an RPE contract and three peers (X, Y and Z) do have an RPE contract. From the latter group, two peers ( $X$ and $Z$ ) also have Firm A self-selected as their peer, resulting in an overlap in peer selection. Therefore, from Firm A's point of view there are two overlapping peers, which is 40 percent of the total peer group.

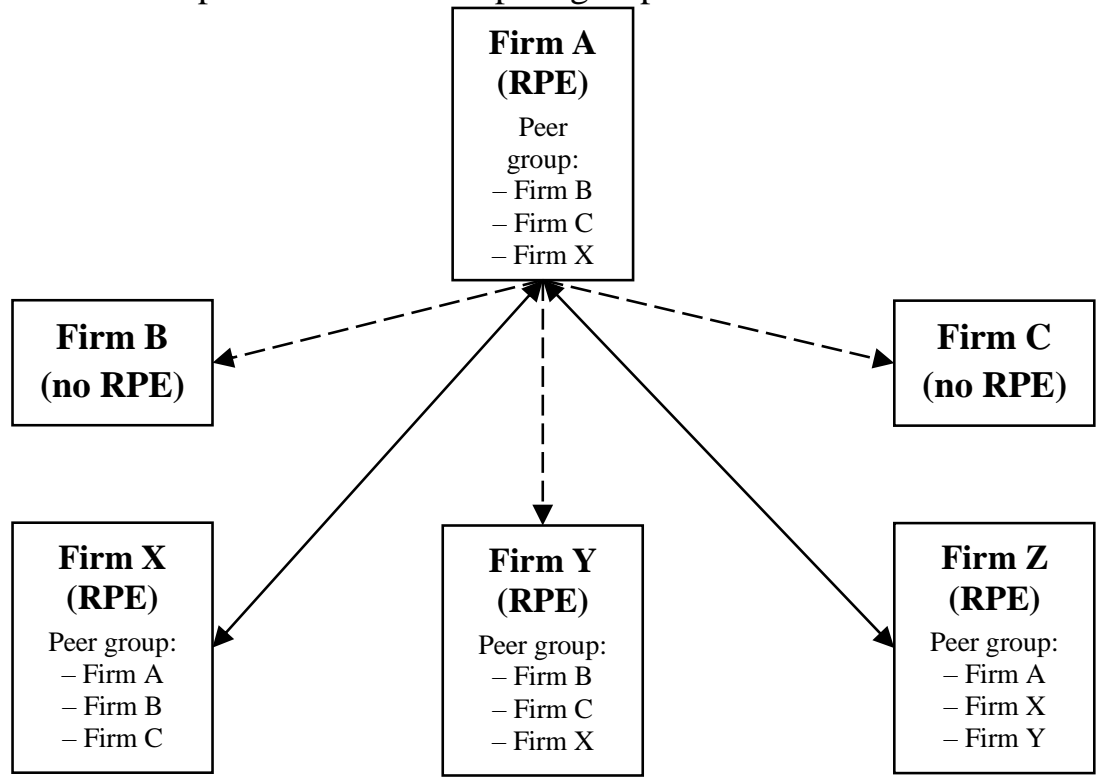

Exogenous Additions

The number of exogenous additions to a peer group for the period indicated by the subscript. An exogenous addition is the event where one firm get selected by another firm as a peer, resulting in an overlap in peer selection, i.e., after the former firm already selected the latter firm as peer.

(continued on next page) 
Table B1 (continued)

This table describes all variables used in this paper and if necessary calculations and external sources.

Panel C: Competitive Environment

Industry Growth

An indicator variable equal to one if the majority of the firms within one industry are in the growth life cycle stage for the period indicated by the subscript, where (i) the life cycle classification follows the cash flow proxy developed by Dickinson (2011), and (ii) the industry classification follows the 48 industry groups identified by Fama and French (1997).

Industry Mature

An indicator variable equal to one if the majority of the firms within one industry are in the mature life cycle stage for the period indicated by the subscript, where (i) the life cycle classification follows the cash flow proxy developed by Dickinson (2011), and (ii) the industry classification follows the 48 industry groups identified by Fama and French (1997).

Panel D: Controls

Peer Group Synchronicity

A proxy for the firm's level of noise reduction in the period indicated by the subscript. Peer Group Synchronicity is computed as the firm's stock return synchronicity with its peers, using a procedure similar as utilized by Durnev et al. (2003), Morck et al. (2000) and Piotroski and Roulstone (2004). Specifically, the firm's daily stock returns are regressed on the daily stock returns for all peers:

$$
\text { Stock Returns }_{i, t}=\alpha_{0}+\beta^{\prime} \sum_{j=1}^{n} \text { Stock Returns }_{j, t}+\varepsilon_{i, t}
$$

where $i, j, t$ index firm, peer and day, respectively. The regression is estimated for each firm-year using 675 daily observations, i.e., for a period of three years, conform the RPE performance period.

Peer Group Synchronicity is then computed as:

$$
\log _{\mathrm{e}}\left(\frac{R^{2}}{1-R^{2}}\right)
$$

where $R^{2}$ is the coefficient of determination from the estimation above. The natural logarithm transformation of $R^{2}$ creates an unbounded continuous variable out of the originally bounded by 0 and 1 variable.

H\&P Number of Peers A proxy for the firm's product market competition in the period indicated by the subscript. $H \& P$ Number of Peers is the natural logarithm of the number of peers a firm competes with in its product market, as defined by Hoberg and Phillips (2010, 2016).

H\&P Peer Similarity A proxy for the firm's product market competition in the period indicated by the subscript. H\&P Peer Similarity is the natural logarithm of the median similarity score of all peers a firm competes with in its product market, as defined by Hoberg and Phillips (2010, 2016).

This proxy supplements $H \& P$ Number of Peers. For example, consider a product market which is small yet intense. In that case, although $H \& P$ Number of Peers is low, $H \& P$ Peer Similarity will be high and pick up the variance of the intense competitive environment.

Size Percentile The firm's size percentile rank in its RPE peer group in the period indicated by the subscript. Size is computed as the natural logarithm of the total assets. 
Table B1 (continued)

This table describes all variables used in this paper and if necessary calculations and external sources.

Panel D: Controls (continued)

Size H\&P Percentile The firm's size percentile rank in its group of product market competitors in the period indicated by the subscript, as defined by Hoberg and Phillips

Tobin's q Percentile (2010, 2016). Size is computed as the natural logarithm of the total assets. The firm's Tobin's q percentile rank in its RPE peer group in the period indicated by the subscript. Tobin's q is computed as the natural logarithm of Tobin's q ratio, calculated by dividing the sum of the firm's equity value, book value of long-term debt, and current liabilities by the total assets.

Tobin's q H\&P Percentile The firm's Tobin's q percentile rank in its group of product market competitors in the period indicated by the subscript, as defined by Hoberg and Phillips (2010,2016). Tobin's q is computed as the natural logarithm of Tobin's q ratio, calculated by dividing the sum of the firm's equity value, book value of long-term debt, and current liabilities by the total assets.

Leverage Percentile The firm's leverage percentile rank in its RPE peer group in the period indicated by the subscript. Leverage is computed as the natural logarithm of debt to equity ratio in the period indicated by the subscript.

Leverage H\&P Percentile The firm's leverage percentile rank in its group of product market competitors in the period indicated by the subscript, as defined by Hoberg and Phillips $(2010,2016)$. Leverage is computed as the natural logarithm of debt to equity ratio in the period indicated by the subscript.

Returns Percentile The firm's stock returns percentile rank in its RPE peer group in the period indicated by the subscript.

Returns H\&P Percentile The firm's stock returns percentile rank in its group of product market competitors in the period indicated by the subscript, as defined by Hoberg and Phillips (2010, 2016).

Loss An indicator variable equal to one if the net income before extraordinary items is negative in the period indicated by the subscript, zero otherwise.

\section{Panel E: Industry Components}

Product Substitutability The extent of product substitutability in an industry for the period indicated by the subscript (Karuna, 2007).

Market Size

The level of market size in an industry for the period indicated by the

Entry Costs

Concentration subscript (Karuna, 2007).

The level of entry costs in an industry for the period indicated by the subscript (Karuna, 2007).

Industry Return on Assets

The four-firm concentration ratio for the period indicated by the subscript (Karuna, 2007).

The average firm's return on assets in an industry for the period indicated by the subscript.

Industry Net Financial

Obligations

The average firm's net financial obligations scaled by assets for the period indicated by the subscript (Dickinson, 2011).

Industry Risk-Taking

The average firm's risk-taking in an industry for the period indicated by the subscript (Armstrong and Vashishtha, 2012).

Industry Investments

The average firm's investment levels in an industry for the period indicated by the subscript (Richardson, 2006). 


\section{REFERENCES}

Agarwal, R., Sarkar, M.B., Echambadi, R., 2002. The conditioning effect of time on firm survival: An industry life cycle approach. Acad. Manage. J. 45, 971-994.

Aggarwal, R.K., Samwick, A.A., 1999a. Executive compensation, strategic competition, and relative performance evaluation: Theory and evidence. J. Financ. 54, 1999-2043.

Aggarwal, R.K., Samwick, A.A., 1999b. The other side of the trade-off: The impact of risk on executive compensation. J. Polit. Econ. 107, 65-105.

Albuquerque, A.M., 2014. Do growth-option firms use less relative performance evaluation? Account. Rev. 89, 27-60.

Ali, A., Klasa, S., Yeung, E., 2014. Industry concentration and corporate disclosure policy. J. Account. Econ. 58, 240-264.

Antle, R., Smith, A., 1986. An empirical investigation of the relative performance evaluation of corporate executives. J. Account. Res. 24, 1-39.

Armstrong, C.S., Vashishtha, R., 2012. Executive stock options, differential risk-taking incentives, and firm value. J. Financ. Econ. 104, 70-88.

Baiman, S., Demski, J.S., 1980. Economically optimal performance evaluation and control systems. J. Account. Res. 18, 184-220.

Barro, J.R., Barro, R.J., 1990. Pay, performance, and turnover of bank CEOs. J. Labor. Econ. 8, 448.

Bizjak, J., Kalpathy, S., Li, Z.F., Young, B., 2018. The role of peer firm selection in explicit relative performance awards, (SSRN Working Paper No. 2833309). 10.2139/ssrn.2833309, pp. 165.

Burgstahler, D., Dichev, I., 1997. Earnings management to avoid earnings decreases and losses. J. Account. Econ. 24, 99-126.

Cantrell, B.W., Dickinson, V., 2018. Conditional life cycle: An examination of operating performance for leaders and laggards. Manage. Sci.

Chen, E.L., Katila, R., McDonald, R., Eisenhardt, K.M., 2010a. Life in the fast lane: Origins of competitive interaction in new vs. established markets. Strateg. Manage. J. 31, 1527-1547.

Chen, M., Lin, H., Michel, J.G., 2010b. Navigating in a hypercompetitive environment: The roles of action aggressiveness and TMT integration. Strateg. Manage. J. 31, 1410-1430.

Covin, J.G., Covin, T.J., 1990. Competitive aggressiveness, environmental context, and small firm performance. Entrep. Theory. Pract. 14, 35-50.

Derfus, P.J., Maggitti, P.G., Grimm, C.M., Smith, K.G., 2008. The red queen effect: Competitive actions and firm performance. Acad. Manage. J. 51, 61-80.

Dickinson, V., 2011. Cash flow patterns as a proxy for firm life cycle. Account. Rev. 86, 19641994.

Durnev, A., Morck, R., Yeung, B., Zarowin, P., 2003. Does greater firm-specific return variation mean more or less informed stock pricing? J. Account. Res. 41, 797-836.

Eisenhardt, K.M., Martin, J.A., 2000. Dynamic capabilities: What are they? Strateg. Manage. J. $21,1105$.

Equilar, 2017. Executive Long-Term Incentive Plans.

Fama, E.F., French, K.R., 1997. Industry costs of equity. J. Financ. Econ. 43, 153-193.

Ferrier, W.J., 2001. Navigating the competitive landscape: The drivers and consequences of competitive aggressiveness. Acad. Manage. J. 44, 858-877. 
Ferrier, W.J., Lyon, D.W., 2004. Competitive repertoire simplicity and firm performance: The moderating role of top management team heterogeneity. Manage. Decis. Econ. 25, 317327.

Ferrier, W.J., Smith, K.G., Grimm, C.M., 1999. The role of competitive action in market share erosion and industry dethronement: A study of industry leaders and challengers. Acad. Manage. J. 42, 372-388.

Forward Air Corporation, 2015. Proxy Statement 2014.

Gibbons, R., Murphy, K.J., 1990. Relative performance evaluation for chief executive officers. Ind. Labor. Rel. Rev. 43, 30-51.

Glaeser, S., 2018. The effects of proprietary information on corporate disclosure and transparency: Evidence from trade secrets. J. Account. Econ. 66, 163-193.

Gong, G., Li, L.Y., Shin, J.Y., 2011. Relative performance evaluation and related peer groups in executive compensation contracts. Account. Rev. 86, 1007-1043.

Gort, M., Klepper, S., 1982. Time paths in the diffusion of product innovations. Econ. J. 92, 630653.

Gow, I.D., Ormazabal, G., Taylor, D.J., 2010. Correcting for cross-sectional and time-series dependence in accounting research. Account. Rev. 85, 483-512.

Hainmueller, J., 2017. Entropy balancing for causal effects: A multivariate reweighting method to produce balanced samples in observational studies. Polit. Anal. 20, 25-46.

Hambrick, D.C., Cho, T.S., Chen, M., 1996. The influence of top management team heterogeneity on firms' competitive moves. Admin. Sci. Quart. 41, 659-684.

Hoberg, G., Phillips, G., 2010. Product market synergies and competition in mergers and acquisitions: A text-based analysis. Rev. Financ. Stud. 23, 3773-3811.

Hoberg, G., Phillips, G., 2016. Text-based network industries and endogenous product differentiation. J. Polit. Econ. 124, 1423-1465.

Holmström, B., 1982. Moral hazard in teams. Bell. J. Econ. 13, 324-340.

Janakiraman, S.N., Lambert, R.A., Larcker, D.F., 1992. An empirical investigation of the relative performance evaluation hypothesis. J. Account. Res. 30, 53-69.

Karuna, C., 2007. Industry product market competition and managerial incentives. J. Account. Econ. 43, 275-297.

Lazear, E.P., Rosen, S., 1981. Rank-order tournaments as optimum labor contracts. J. Polit. Econ. 89, 841-864.

Lumpkin, G.T., Dess, G.G., 1996. Clarifying the entrepreneurial orientation construct and linking it to performance. Acad. Manage. Rev. 21, 135-172.

Matsumura, E.M., Shin, J.Y., 2006. An empirical analysis of an incentive plan with relative performance measures: Evidence from a postal service. Account. Rev. 81, 533-566.

Morck, R., Yeung, B., Yu, W., 2000. The information content of stock markets: why do emerging markets have synchronous stock price movement? J. Financ. Econ. 58, 215-260.

Nadkarni, S., Chen, T., Chen, J., 2016. The clock is ticking! Executive temporal depth, industry velocity, and competitive aggressiveness. Strateg. Manage. J. 37, 1132-1153.

Ndofor, H.A., Sirmon, D.G., He, X., 2011. Firm resources, competitive actions and performance: Investigating a mediated model with evidence from the in-vitro diagnostics industry. Strateg. Manage. J. 32, 640-657.

Park, J., Sani, J., Shroff, N., White, H., 2019. Disclosure incentives when competing firms have common ownership. J. Account. Econ (forthcoming)

Park, H., Vrettos, D., 2015. The moderating effect of relative performance evaluation on the risk incentive properties of executives' equity portfolios. J. Account. Res. 53, 1055-1108. 
Peltoniemi, M., 2011. Reviewing industry life-cycle theory: Avenues for future research. Int. J. Manag. Rev. 13, 349-375.

Petersen, M.A., 2009. Estimating standard errors in finance panel data sets: Comparing approaches. Rev. Financ. Stud. 22, 435-480.

Piotroski, J.D., Roulstone, D.T., 2004. The influence of analysts, institutional investors, and insiders on the incorporation of market, industry, and firm-specific information into stock prices. Account. Rev. 79, 1119-1151.

Roychowdhury, S., 2006. Earnings management through real activities manipulation. J. Account. Econ. 42, 335-370.

Richardson, S., 2006. Over-investment of free cash flow. Rev. Account. Stud. 11, 159-189.

Rindova, V., Ferrier, W.J., Wiltbank, R., 2010. Value from gestalt: How sequences of competitive actions create advantage for firms in nascent markets. Strateg. Manage. J. 31, 1474-1497.

Unit Corporation, 2015. Proxy Statement 2014.

Vrettos, D., 2013. Are relative performance measures in CEO incentive contracts used for risk reduction and/or for strategic interaction? Account. Rev. 88, 2179-2212.

Young, G., Smith, K.G., Grimm, C.M., 1996. 'Austrian' and industrial organization perspective on firm-level competitive activity and performance. Organ. Sci. 7, 243-254. 


\section{Table 1}

This table presents summary statistics for the full sample. Panel A presents summary statistics for the full RPE sample. Panel B presents $t$-tests for differences in mean summary statistics between RPE firms with and without peer group overlap. All variables are defined in Appendix B.

\begin{tabular}{|c|c|c|c|c|c|c|c|}
\hline \multicolumn{8}{|c|}{ Panel A: Summary Statistics for Full RPE Sample } \\
\hline & Mean & Std. Dev. & Min & 10th & Median & 90th & Max \\
\hline \multicolumn{8}{|l|}{ Aggressiveness } \\
\hline Aggressiveness Volume & 16.427 & 18.642 & 0.000 & 0.000 & 9.000 & 49.000 & 64.000 \\
\hline $\log _{e}$ Aggressiveness Volume & 2.204 & 1.256 & 0.000 & 0.000 & 2.303 & 3.912 & 4.174 \\
\hline Aggressiveness Complexity & 0.317 & 0.267 & 0.000 & 0.000 & 0.364 & 0.667 & 0.889 \\
\hline Aggressiveness Deviance & 0.158 & 0.172 & 0.000 & 0.009 & 0.089 & 0.381 & 0.902 \\
\hline \multicolumn{8}{|l|}{ Peer Group Attributes } \\
\hline Peer Group Overlap & 0.140 & 0.164 & 0.000 & 0.000 & 0.083 & 0.378 & 0.727 \\
\hline Peer Group Synchronicity & 0.500 & 0.718 & -2.396 & -0.426 & 0.564 & 1.350 & 2.101 \\
\hline Exogenous Additions Indicator & 0.092 & 0.289 & 0.000 & 0.000 & 0.000 & 0.000 & 1.000 \\
\hline \multicolumn{8}{|l|}{ Competitive Environment } \\
\hline Industry Introduction & 0.085 & 0.280 & 0.000 & 0.000 & 0.000 & 0.000 & 1.000 \\
\hline Industry Growth & 0.511 & 0.500 & 0.000 & 0.000 & 1.000 & 1.000 & 1.000 \\
\hline Industry Mature & 0.404 & 0.491 & 0.000 & 0.000 & 0.000 & 1.000 & 1.000 \\
\hline \multicolumn{8}{|l|}{ Controls } \\
\hline H\&P Number of Peers & 3.733 & 1.348 & 0.693 & 1.946 & 3.773 & 5.458 & 6.052 \\
\hline H\&P Peer Similarity & 0.029 & 0.020 & 0.000 & 0.009 & 0.024 & 0.062 & 0.089 \\
\hline Size Percentile & 0.429 & 0.221 & 0.000 & 0.123 & 0.429 & 0.740 & 1.000 \\
\hline Tobin's q Percentile & 0.430 & 0.277 & 0.000 & 0.056 & 0.436 & 0.800 & 1.000 \\
\hline Leverage Percentile & 0.441 & 0.270 & 0.000 & 0.077 & 0.429 & 0.800 & 1.000 \\
\hline Returns Percentile & 0.447 & 0.284 & 0.000 & 0.058 & 0.444 & 0.833 & 1.000 \\
\hline Loss & 0.100 & 0.301 & 0.000 & 0.000 & 0.000 & 0.300 & 1.000 \\
\hline
\end{tabular}

Panel A: Summary Statistics Comparison within RPE Sample

$\begin{array}{cc}\text { Mean Value for } & \text { Mean Value for } \\ \text { RPE with Overlap } & \text { RPE without Overlap }\end{array}$

\begin{tabular}{lccc}
\hline Aggressiveness & & & \\
log $_{e}$ Aggressiveness Volume & 2.234 & 2.193 & 0.320 \\
Aggressiveness Complexity & 0.331 & 0.288 & 1.600 \\
Aggressiveness Deviance & 16.170 & 15.637 & 0.115 \\
Peer Group Attributes & & & \\
Peer Group Overlap & 0.210 & 0.000 & $23.292^{* * *}$ \\
Peer Group Synchronicity & 0.706 & 0.081 & $8.324^{* * *}$ \\
Competitive Environment & & & \\
Industry Introduction & 0.114 & 0.034 & $3.450^{* * *}$ \\
Industry Growth & 0.622 & 0.284 & $-9.331^{* * *}$ \\
Industry Mature & 0.263 & 0.682 & \\
Controls & & & $6.169^{* * * *}$ \\
H\&P Number of Peers & 4.026 & 3.200 & $7.396^{* * *}$ \\
H\&P Peer Similarity & 0.033 & 0.020 & $4.415^{* * *}$ \\
Size Percentile & 0.461 & 0.361 & $-2.660^{* * *}$ \\
Tobin's q Percentile & 0.410 & 0.482 & $3.831^{* * *}$ \\
Leverage Percentile & 0.471 & 0.372 & 0.417 \\
Returns Percentile & 0.452 & 0.440 & $3.103^{* * *}$ \\
Loss & 0.127 & 0.047 & \\
\hline
\end{tabular}


Table 2

This table presents Pearson's correlations coefficients between the independent variables. Bold indicates significance at a two-tailed probability level of 5\%, or better. All variables are defined in Appendix B.

\begin{tabular}{|c|c|c|c|c|c|c|c|c|c|c|c|c|c|c|c|c|c|}
\hline & & $\mathrm{A}$ & B & $\mathrm{C}$ & $\mathrm{D}$ & $\mathrm{E}$ & $\mathrm{F}$ & $\mathrm{G}$ & $\mathrm{H}$ & $\mathrm{I}$ & $\mathrm{J}$ & $\mathrm{K}$ & $\mathrm{L}$ & $\mathrm{M}$ & $\mathrm{N}$ & $\mathrm{O}$ & $\mathrm{P}$ \\
\hline Aggressiveness Volume & $\mathrm{A}$ & & & & & & & & & & & & & & & & \\
\hline $\log _{e}$ Aggressiveness Volume & $\mathrm{B}$ & 0.86 & & & & & & & & & & & & & & & \\
\hline Aggressiveness Complexity & $\mathrm{C}$ & 0.41 & 0.54 & & & & & & & & & & & & & & \\
\hline Aggressiveness Deviance & $\mathrm{D}$ & -0.43 & -0.59 & -0.36 & & & & & & & & & & & & & \\
\hline Peer Group Overlap & $\mathrm{E}$ & 0.08 & 0.14 & 0.17 & -0.01 & & & & & & & & & & & & \\
\hline Peer Group Synchronicity & $\mathrm{F}$ & $-\mathbf{0 . 1 0}$ & -0.11 & 0.04 & 0.09 & 0.27 & & & & & & & & & & & \\
\hline Exogenous Additions Indicator & $\mathrm{G}$ & -0.04 & 0.01 & 0.04 & 0.03 & 0.32 & 0.16 & & & & & & & & & & \\
\hline Industry Introduction & $\mathrm{H}$ & 0.02 & 0.07 & 0.04 & -0.10 & -0.08 & -0.06 & -0.10 & & & & & & & & & \\
\hline Industry Growth & I & -0.10 & -0.07 & 0.01 & 0.09 & 0.44 & 0.30 & 0.28 & NA & & & & & & & & \\
\hline Industry Mature & $\mathbf{J}$ & 0.09 & 0.03 & -0.03 & -0.04 & -0.40 & -0.27 & -0.23 & NA & NA & & & & & & & \\
\hline H\&P Number of Peers & $\mathrm{K}$ & 0.03 & 0.07 & 0.09 & 0.02 & 0.44 & 0.16 & 0.20 & -0.09 & 0.45 & $-\mathbf{0 . 4 0}$ & & & & & & \\
\hline H\&P Peer Similarity & $\mathrm{L}$ & 0.02 & 0.05 & 0.05 & 0.05 & 0.42 & 0.02 & 0.16 & -0.09 & 0.31 & -0.27 & 0.43 & & & & & \\
\hline Size Percentile & M & 0.23 & 0.19 & 0.22 & -0.09 & 0.12 & 0.26 & 0.06 & -0.01 & -0.10 & 0.11 & -0.01 & -0.08 & & & & \\
\hline Tobin's q Percentile & $\mathrm{N}$ & 0.01 & 0.05 & 0.05 & -0.07 & 0.04 & 0.00 & $-\mathbf{0 . 1 0}$ & 0.02 & 0.01 & -0.01 & -0.10 & -0.04 & $-\mathbf{0 . 1 8}$ & & & \\
\hline Leverage Percentile & $\mathrm{O}$ & 0.11 & 0.07 & 0.03 & 0.01 & 0.13 & 0.04 & 0.03 & 0.02 & -0.01 & -0.01 & -0.05 & 0.06 & 0.24 & -0.04 & & \\
\hline Returns Percentile & $\mathrm{P}$ & -0.04 & 0.00 & 0.00 & 0.01 & 0.02 & 0.11 & -0.05 & 0.01 & 0.04 & -0.05 & 0.01 & -0.02 & -0.05 & 0.26 & 0.02 & \\
\hline Loss & Q & -0.07 & -0.03 & -0.04 & 0.02 & 0.12 & -0.03 & 0.04 & 0.08 & 0.04 & -0.09 & 0.10 & 0.16 & 0.06 & -0.24 & 0.06 & -0.09 \\
\hline
\end{tabular}


Table 3

This table provides results examining the effect of peer group overlap on competitive aggressiveness, and tests H1. Competitive aggressiveness is measured as the firm's competitive volume and complexity. Volume captures the total number of competitive actions and complexity captures the extent to which a firm's repertoire of actions is composed of actions of different types. Considering that competitive aggressiveness is contingent on the competitive environment, the equations are estimated separately for different competitive environment, as proxied by the industry life cycle. Columns (1) and (2) present the results for the growth cycle, and columns (3) and (4) present the results for the mature cycle. The equations are estimated using seemingly unrelated regressions models. The industry indicators follow the 48 industry groups identified by Fama and French (1997). * ** and *** indicate significance at two-tailed probability levels of 10\%, 5\%, and 1\%, respectively. All variables are defined in Appendix B.

\begin{tabular}{|c|c|c|c|c|c|c|c|c|}
\hline \multirow[b]{5}{*}{$\log _{e}$ Aggressiveness Volume ${ }_{t}$} & \multicolumn{2}{|c|}{ (1) } & \multicolumn{2}{|c|}{ (2) } & \multicolumn{2}{|c|}{ (3) } & \multicolumn{2}{|c|}{ (4) } \\
\hline & \multicolumn{4}{|c|}{ Industry Growth Cycle } & \multicolumn{4}{|c|}{ Industry Mature Cycle } \\
\hline & \multirow{2}{*}{\multicolumn{2}{|c|}{$\begin{array}{c}\log _{e} \text { Aggressiveness }^{\text {Aglume }} \\
\text { Volume }_{t}\end{array}$}} & \multirow{2}{*}{\multicolumn{2}{|c|}{$\begin{array}{c}\text { Aggressiveness } \\
\text { Complexity }_{t}\end{array}$}} & \multirow{2}{*}{\multicolumn{2}{|c|}{$\begin{array}{c}\log _{e} \text { Aggressiveness } \\
\text { Volume }_{t}\end{array}$}} & \multirow{2}{*}{\multicolumn{2}{|c|}{$\begin{array}{c}\text { Aggressiveness } \\
\text { Complexity }_{t}\end{array}$}} \\
\hline & & & & & & & & \\
\hline & & & $0.092 * * *$ & $(0.018)$ & & & $0.140 * * *$ & $(0.015)$ \\
\hline Peer Group Overlap ${ }_{t}$ & $1.009 * *$ & $(0.444)$ & 0.011 & $(0.098)$ & -1.229 & $(0.958)$ & $0.616 * * *$ & $(0.209)$ \\
\hline Peer Group Synchronicity ${ }_{t}$ & -0.170 & $(0.135)$ & $-0.054 *$ & $(0.030)$ & $0.292 * *$ & $(0.137)$ & $0.056^{*}$ & $(0.030)$ \\
\hline H\&P Number of Peers $t-1$ & $0.188 *$ & $(0.096)$ & -0.004 & $(0.021)$ & -0.025 & $(0.086)$ & $-0.061 * * *$ & $(0.019)$ \\
\hline H\&P Median Similarity S $_{t-1}$ & -6.707 & $(4.919)$ & -0.607 & $(1.083)$ & $-11.695 * *$ & $(4.659)$ & -0.386 & $(1.031)$ \\
\hline Size Percentile $_{t-1}$ & $0.661 *$ & $(0.339)$ & $0.162 * *$ & $(0.075)$ & $1.060 * *$ & $(0.428)$ & 0.047 & $(0.095)$ \\
\hline Tobin's q Percentile $_{t-1}$ & -0.242 & $(0.253)$ & 0.080 & $(0.056)$ & $0.824 * * *$ & $(0.312)$ & -0.046 & $(0.069)$ \\
\hline Leverage Percentile $_{t-1}$ & -0.187 & $(0.251)$ & -0.087 & $(0.055)$ & 0.086 & $(0.358)$ & $-0.134 *$ & $(0.077)$ \\
\hline Returns Percentile $_{t-1}$ & 0.068 & $(0.226)$ & -0.042 & $(0.050)$ & -0.030 & $(0.265)$ & 0.048 & $(0.057)$ \\
\hline $\operatorname{Loss}_{t-1}$ & 0.088 & $(0.218)$ & 0.006 & $(0.048)$ & -0.210 & $(0.315)$ & -0.064 & $(0.068)$ \\
\hline Constant & 0.042 & $(0.557)$ & 0.075 & $(0.122)$ & $1.958 * *$ & $(0.838)$ & $0.556 * * *$ & $(0.185)$ \\
\hline Year Indicators & \multicolumn{2}{|c|}{ Yes } & \multicolumn{2}{|c|}{ Yes } & \multicolumn{2}{|c|}{ Yes } & \multicolumn{2}{|c|}{ Yes } \\
\hline Industry Indicators & \multicolumn{2}{|c|}{ Yes } & \multicolumn{2}{|c|}{ Yes } & \multicolumn{2}{|c|}{ Yes } & \multicolumn{2}{|c|}{ Yes } \\
\hline Observations & \multicolumn{2}{|c|}{236} & \multicolumn{2}{|c|}{236} & \multicolumn{2}{|c|}{174} & \multicolumn{2}{|c|}{174} \\
\hline Adjusted $R^{2}$ & \multicolumn{2}{|c|}{$36.518 \%$} & \multicolumn{2}{|c|}{$36.084 \%$} & \multicolumn{2}{|c|}{$53.352 \%$} & \multicolumn{2}{|c|}{$47.704 \%$} \\
\hline
\end{tabular}




\section{Table 4}

This table provides results examining the effect of exogenous changes in peer group overlap on competitive aggressiveness, for firms in the industry growth cycle. Competitive aggressiveness is measured as the firm's competitive volume and complexity. Volume captures the total number of competitive actions and complexity captures the extent to which a firm's repertoire of actions is composed of actions of different types. Column (3) presents weighted $t$-tests for differences in mean competitive aggressiveness between RPE firms that were affected by an exogenous peer group addition ("treatment"), and RPE firms without peer group overlap ("control"). The control group is entropy balanced to the treatment group using the significant covariates of the main analysis, i.e., Size, Tobin's q, Year Indicators, and Industry Indicators. In addition, the sample is balanced on the natural log of Aggressiveness Volume and Aggressiveness Complexity in year $t .{ }^{*}, * *$ and $* * *$ indicate significance at one-tailed probability levels of $10 \%, 5 \%$, and $1 \%$, respectively. All variables are defined in Appendix B.

\begin{tabular}{|c|c|c|c|}
\hline & (1) & (2) & (3) \\
\hline & Treatment in $t+1$ & Control in $t+1$ & Weighted $t$-test \\
\hline Aggressiveness Volume & 2.743 & 2.353 & $1.408^{*}$ \\
\hline Aggressiveness Complexity & 0.413 & 0.336 & 1.155 \\
\hline
\end{tabular}


Table 5

This table provides results examining the effect of RPE on competitive aggressiveness. RPE firms are compared to non-RPE firms, and are separated into RPE firms with and without peer group overlap. Competitive aggressiveness is measured as the firm's competitive volume and complexity. Volume captures the total number of competitive actions and complexity captures the extent to which a firm's repertoire of actions is composed of actions of different types. Considering that competitive aggressiveness is contingent on the competitive environment, the equations are estimated separately for different competitive environment, as proxied by the industry life cycle. Columns (1) and (2) present the results for the growth cycle, and columns (3) and (4) present the results for the mature cycle. The equations are estimated using seemingly unrelated regressions models. The industry indicators follow the 48 industry groups identified by Fama and French (1997). *,** and *** indicate significance at two-tailed probability levels of $10 \%, 5 \%$, and 1\%, respectively. All variables are defined in Appendix B.

\begin{tabular}{|c|c|c|c|c|c|c|c|c|}
\hline \multirow{5}{*}{$\begin{array}{l} \\
\log _{e} \text { Aggressiveness Volume }_{t}\end{array}$} & \multicolumn{2}{|c|}{ (1) } & \multicolumn{2}{|c|}{ (2) } & \multicolumn{2}{|c|}{ (3) } & \multicolumn{2}{|c|}{ (4) } \\
\hline & \multirow{3}{*}{\multicolumn{2}{|c|}{$\begin{array}{c}\text { Industry } \\
\log _{e} \text { Aggressiveness } \\
\text { Volume }_{t}\end{array}$}} & \multicolumn{2}{|c|}{ Growth Cycle } & \multicolumn{4}{|c|}{ Industry Mature Cycle } \\
\hline & & & \multirow{2}{*}{\multicolumn{2}{|c|}{$\begin{array}{l}\text { Aggressiveness } \\
\text { Complexity }_{t}\end{array}$}} & \multirow{2}{*}{\multicolumn{2}{|c|}{$\begin{array}{c}\log _{e} \text { Aggressiveness }_{\text {Volume }_{t}} \\
\text { Vols }\end{array}$}} & \multirow{2}{*}{\multicolumn{2}{|c|}{$\begin{array}{l}\text { Aggressiveness } \\
\text { Complexity }_{t}\end{array}$}} \\
\hline & & & & & & & & \\
\hline & & & $0.140 * * *$ & $(0.009)$ & & & $0.125 * * *$ & $(0.006)$ \\
\hline $\mathrm{RPE}_{t}$ & 0.066 & $(0.135)$ & 0.017 & $(0.026)$ & $0.317 * * *$ & $(0.101)$ & $-0.037 *$ & $(0.020)$ \\
\hline $\mathrm{RPE}_{t} \times$ Peer Group Overlap $t$ & $0.856^{* *}$ & $(0.417)$ & -0.012 & $(0.081)$ & $-2.097 * *$ & $(0.821)$ & $0.339 * *$ & $(0.163)$ \\
\hline H\&P Number of Peers $s_{t-1}$ & $0.087^{*}$ & $(0.051)$ & -0.011 & $(0.010)$ & $-0.059 *$ & $(0.031)$ & $-0.019 * * *$ & $(0.006)$ \\
\hline H\&P Median Similarity $t-1$ & -0.405 & (3.284) & 0.358 & $(0.636)$ & -3.190 & $(2.346)$ & 0.5 & $(0.465)$ \\
\hline Size H\&P Percentile $t_{t-1}$ & $0.972 * * *$ & $(0.193)$ & $0.096 * *$ & $(0.038)$ & $1.678 * * *$ & $(0.155)$ & $0.135^{* * *}$ & $(0.032)$ \\
\hline Tobin's q H\&P Percentile $e_{t-1}$ & -0.110 & $(0.184)$ & -0.01 & $(0.036)$ & $0.499 * * *$ & $(0.125)$ & $-0.043 *$ & $(0.025)$ \\
\hline Leverage H\&P Percentile $_{t-1}$ & 0.023 & $(0.199)$ & -0.024 & $(0.039)$ & 0.187 & $(0.141)$ & 0.006 & $(0.028)$ \\
\hline Stock Returns H\&P Percentile ${ }_{t-1}$ & -0.128 & $(0.179)$ & -0.05 & $(0.035)$ & 0.135 & $(0.119)$ & 0.001 & $(0.024)$ \\
\hline $\operatorname{Loss}_{t-1}$ & -0.069 & $(0.166)$ & $0.054 *$ & $(0.032)$ & -0.092 & $(0.100)$ & 0.026 & $(0.020)$ \\
\hline Constant & 0.243 & $(0.793)$ & $0.349 * *$ & $(0.154)$ & $1.361 * *$ & $(0.588)$ & $0.196 *$ & $(0.117)$ \\
\hline Year Indicators & \multicolumn{2}{|c|}{ Yes } & \multicolumn{2}{|c|}{ Yes } & \multicolumn{2}{|c|}{ Yes } & \multicolumn{2}{|c|}{ Yes } \\
\hline Industry Indicators & \multicolumn{2}{|c|}{ Yes } & \multicolumn{2}{|c|}{ Yes } & \multicolumn{2}{|c|}{ Yes } & \multicolumn{2}{|c|}{ Yes } \\
\hline Observations & \multicolumn{2}{|c|}{502} & \multicolumn{2}{|c|}{502} & \multicolumn{2}{|c|}{1,043} & \multicolumn{2}{|c|}{1,043} \\
\hline Adjusted $R^{2}$ & \multicolumn{2}{|c|}{$35.160 \%$} & \multicolumn{2}{|c|}{$42.424 \%$} & \multicolumn{2}{|c|}{$47.090 \%$} & \multicolumn{2}{|c|}{$47.430 \%$} \\
\hline
\end{tabular}




\section{Table 6}

This table provides results examining the effect of peer group overlap on competitive aggressiveness, using an alternative aggressiveness dimension. Competitive aggressiveness is measured as the firm's competitive deviance. Deviance captures the extent to which a firm's competitive repertoire deviates from industry norms. Considering that competitive aggressiveness is contingent on the competitive environment, the equations are estimated separately for different competitive environment, as proxied by the industry life cycle. Column (1) presents the results for the growth cycle, and column (2) presents the results for the mature cycle. The equations are estimated using seemingly unrelated regressions models, in conjunction with the equations in Table 3. The industry indicators follow the 48 industry groups identified by Fama and French (1997).*,** and *** indicate significance at two-tailed probability levels of $10 \%, 5 \%$, and 1\%, respectively. All variables are defined in Appendix B.

(1)

Industry Growth Cycle Industry Mature Cycle

\begin{tabular}{|c|c|c|c|c|}
\hline Peer Group Overlap ${ }_{t}$ & -0.094 & $(0.073)$ & $0.376^{* *}$ & $(0.169)$ \\
\hline Peer Group Synchronicity $_{t}$ & 0.015 & $(0.022)$ & -0.029 & $(0.024)$ \\
\hline $\mathrm{H} \& \mathrm{P}$ Number of Peers $\mathrm{s}_{t-1}$ & -0.001 & $(0.016)$ & 0.013 & $(0.015)$ \\
\hline H\&P Median Similarity ${ }_{t-1}$ & 0.421 & $(0.804)$ & $1.553^{*}$ & $(0.820)$ \\
\hline Size Percentile $t-1$ & -0.021 & $(0.055)$ & $-0.162 * *$ & $(0.075)$ \\
\hline Tobin's q Percentile ${ }_{t-1}$ & 0.010 & $(0.041)$ & $-0.102 *$ & $(0.055)$ \\
\hline Leverage Percentile $_{t-1}$ & 0.018 & $(0.041)$ & 0.065 & $(0.063)$ \\
\hline Returns Percentile $_{t-1}$ & 0.022 & $(0.037)$ & 0.006 & $(0.047)$ \\
\hline $\operatorname{Loss}_{t-1}$ & -0.017 & $(0.036)$ & -0.042 & $(0.055)$ \\
\hline Constant & 0.294 & $(0.091)$ & 0.139 & $(0.148)$ \\
\hline Year Indicators & & Yes & \multicolumn{2}{|c|}{ Yes } \\
\hline Industry Indicators & & Yes & \multicolumn{2}{|c|}{ Yes } \\
\hline Observations & & 236 & \multicolumn{2}{|c|}{174} \\
\hline Adjusted $R^{2}$ & & $10.113 \%$ & \multicolumn{2}{|c|}{$20.688 \%$} \\
\hline
\end{tabular}




\section{Table 7}

This table provides results examining fundamental differences between the underlying components that form competitive environments. Column (1) presents fundamentals for the growth cycle, and column (2) presents fundamentals for the mature cycle. Column (3) presents $t$-tests for differences in mean fundamentals between the growth and mature cycle. $* * *$ and $* * *$ indicate significance at two-tailed probability levels of $10 \%, 5 \%$, and 1\%, respectively. All variables are defined in Appendix B.

\begin{tabular}{lrrr} 
& & & $(3)$ \\
& Industry Growth Cycle & Industry Mature Cycle & \multicolumn{1}{c}{$t$-test } \\
\hline H\&P Number of Peers & 110.105 & 54.456 & $7.009^{* * *}$ \\
H\&P Median Similarity & 0.034 & 0.022 & $6.620^{* * *}$ \\
Product Substitutability & 1.276 & 1.202 & $6.566^{* * *}$ \\
Market Size & 14.38 & 13.369 & $9.891^{* * *}$ \\
Entry Costs & 11.066 & 9.671 & $12.150^{* * *}$ \\
Concentration & 0.424 & 0.504 & $-5.671^{* * *}$ \\
Industry Return on Assets & 0.043 & 0.049 & $-2.386^{* *}$ \\
Industry Net Financial Obligations & $10,886.619$ & $-17,739.223$ & $7.202^{* * *}$ \\
Industry Risk-Taking & 1.694 & 1.134 & $11.536^{* * *}$ \\
Industry Investments & 1.895 & 1.132 & $8.805^{* * *}$ \\
\hline
\end{tabular}

